\title{
Examination of Exercise Addiction Levels of Physical Education Teacher Candidates According to Some Variables
}

\section{Ozan ESMER}

Asist. Prof., School of Physical Education and Sports, Mardin Artuklu University, Mardin, Turkey. Email:ozanesmer@gmail.com

\section{Abstract}

The aim of this study is to examine the levels of exercise addiction of students studying in Physical Education Teaching Program according to gender and academic success variable. The research group consists of 50 students studying in the first class of Mardin Artuklu University, School of Physical Education and Sports, Physical Education Teaching Program in the 2019-2020 academic year. "Exercise Addiction Scale" was used as a data collection tool. The academic success levels of the students are taken from the university's automation system. It was determined that more than half of the participants $(\% 52,0)$ were addicted to exercise. The addiction scores of male students were higher than female students. A low negative correlation was found between gender and exercise addiction scores. A low level of positive correlation was found between academic success and exercise addiction. As a result; A positive, albeit low, relationship was found between academic success and exercise addiction.

Keywords: Physical education teaching, Sports, Exercise, Addiction, Gender, University students, Academic success

Citation I Ozan ESMER (2020). Examination of Exercise Addiction Levels of Physical Education Teacher Candidates According to Some Variables. Asian Journal of Education and Training, 6(2): 274-277.

History:

Recived: 29 January 2020

Revised: 13 March 2020

Accepted: 20 April 2020

Published: 14 May 2020

Licensed: This work is licensed under a Creative Commons

Attribution 3.0 License (cc)

Publisher: Asian Online Journal Publishing Group
Funding: This study received no specific financial support.

Competing Interests: The author declares that there are no conflicts of interests regarding the publication of this paper.

Transparency: The author confirms that the manuscript is an honest, accurate, and transparent account of the study was reported; that no vital features of the study have been omitted; and that any discrepancies from the study as planned have been explained.

Ethical: This study follows all ethical practices during writing.

\section{Contents}

1. Introduction

References.. 


\section{Contribution of this paper to the literature}

This study contributes to the existing literature by examining the levels of exercise addiction of students studying in Physical Education and Sports Teaching program and the effect of this addiction on academic success.

\section{Introduction}

As with every subject, overdoing in sports and exercise causes some negative situations. The desire to do extreme sports is described as "exercise addiction". Nonfunctional exercise habits can lead physical and psychological harm, for instance in the form of overuse injuries and withdrawal symptoms when incapacitate of exercise (Hausenblas \& Symons, 2002a; Landolfi, 2013). Dependency or addiction (Berczik et al., 2012) is expressed as an unavoidable desire for a person, being or object, although it harms the individual psychologically or physically. The addiction, which is examined by dividing it into different categories for a long time, is considered as a whole today and evaluated together with its physical, spiritual and physiological aspects. In addition to behaviors such as playing computer games, sexual activities, food, internet use and gambling, it is possible for exercise to become addictive over time (De Coverley, 1987).

Regular physical activities have many benefits on physiological, physical and mental health. Exercise is important in many aspects of psychological and sociological issues such as improving work performance, selfesteem, positive thinking, a more energetic mood and increased self-confidence (Uz, 2015). In addition, excessive and uncontrollable physical activity is referred to as "exercise addiction" (Yıldırım \& Yıldırım, 2016). However, increasing every exercise intensity and frequency should not be interpreted as exercise addiction (Freimuth, Moniz, \& Kim, 2011). In the spare time of the individual, the desire to exercise with a strong feeling is considered as exercise addiction (Fox \& Boutcher, 2004). Exercise addiction is considered as increasing violence, frequency and duration in physical activity by ignoring the individual's schedule repeatedly (Vardar, Vardar, \& Toksöz, 2012).

Researchers evaluate exercise addiction in two groups as negative and positive addiction. Negative addiction is when people who exercise too much can not exercise, such as depression, anxiety, insomnia and irritability; positive addiction, on the other hand, is expressed as an excessive amount of exercise in order to overcome the difficulties people face in their lives (Adams \& Kirkby, 2002; Bavll, Kozanoğlu, \& Doğanay, 2011). It is stated that this addiction level decreases with advancing age and individuals adopt a more orderly life style (Sussman, Arpawong, Sun, Tsai, \& Rohrbach, 2011).

Physical Education and Sports Teaching program is the primary source of educating of sports teachers who will teach at every level schools in all countries. Future teacher candidates are expected to be well-equipped, selffulfilling and self-confident. In many studies, it has been revealed that students studying in Physical Education and Sports departments are more adequate in many social fields than students in other departments of the university (Altun, 2019; Ozgül, Kangalgil, \& Yıldız, 2019).

The definition of the term exercise addiction, the data obtained from the studies and their evaluation show that the subject is still open to debate. Therefore, more studies need to be carried out in different populations and groups for the causes, treatment and prevention of exercise addiction (Chapman \& De Castro, 1990).

This study was carried out in Mardin Artuklu University, School of Physical Education and Sports. The aim of the study is to examine the levels of exercise addiction of students studying in Physical Education and Sports Teaching program in terms of gender and academic success variables.

\section{Method}

\subsection{Participants}

The participants of the study consist of 50 students who are studying in the first year and actively attending school in Mardin Artuklu University, School of Physical Education and Sports, Physical Education and Sports Teaching in the 2019-2020 academic year. Actually, there are 58 students in that program but 8 are absent and don't attend to school.

\subsection{Collection of Data}

The first-semester grade point average (for academic success variable) of 2019-20 academic year and the gender distributions of students studying in the Physical Education and Sports Teaching program were taken from the university's automation system.

As a data collection tool, "Exercise Addiction Scale" consisting of 17 items developed by Tekkursun and colleagues was used (Tekkurşun, Hazar, \& Cicioğlu, 2018). Researchers found the Cronbach Alpha reliability coefficient of the scale as 0,90. Table 1 shows the exercise addiction score ranges (Tekkurşun et al., 2018).

Table-1. Exercise addiction scale evaluation chart.

\begin{tabular}{l|c|c|l}
\hline Options & Points & Score Range & Scale Evaluation \\
\hline I strongly disagree & 1 & $1-17$ & Normal group \\
\hline Partly disagree & 2 & $18-34$ & Low risk group \\
\hline I agree moderately & 3 & $35-51$ & Risk group \\
\hline I agree & 4 & $52-69$ & Addicted group \\
\hline I strongly agree & 5 & $70-85$ & High level addicted group \\
\hline
\end{tabular}

\subsection{Data Analysis}

One sample "Kolmogorov-Smirnov" test was used to find out whether the data had a normal distribution or not. As a result of this test, it was understood that the data had normal distribution. Parametric test methods (independent T- Test and Pearson Correlation Test) were used in SPSS 24.0 package program for windows for analyzing. 


\section{Findings}

Exercise addiction levels of the participants are given in the table below.

Table 2. Exercise addiction scores of students

\begin{tabular}{c|c|c|c|c}
\hline \multicolumn{2}{|c|}{} & Frequency & Valid Percent & Cumulative Percent \\
\hline \multirow{4}{*}{ Exercise Addiction Level } & $18-34$ & 2 & 4,0 & 4,0 \\
\cline { 2 - 5 } & $35-51$ & 19 & 38,0 & 42,0 \\
\cline { 2 - 5 } & $52-69$ & 26 & 52,0 & 94,0 \\
\cline { 2 - 5 } & $70-85$ & 3 & 6,0 & 100,0 \\
\cline { 2 - 5 } & Total & 50 & 100,0 & \\
\hline
\end{tabular}

There is no one in the normal group (1- 17) among the participants. \%4 of the participants were in the low-risk group, $\% 38$ were in the risk group, $\% 52$ were in the addicted group and $\% 3$ were in the highly addicted group.

Table-3. T Test for exercise addiction levels according to gender.

\begin{tabular}{|c|c|c|c|c|c|c|}
\hline & Gender & $\mathbf{N}$ & $\overline{\boldsymbol{x}}$ & Sd & $\mathbf{t}$ & $\mathbf{P}$ \\
\hline \multirow{2}{*}{ Exercise Addiction Level } & Male & 28 & 54,2500 & 9,04567 & 0,550 & 0,585 \\
\hline & Female & 22 & 52,7273 & 10,51612 & 0,540 & 0,592 \\
\hline
\end{tabular}

In Table 3, exercise addiction scores of the students of Physical Education and Sports Teaching program according to their gender were examined with the independent $t$ test. As a result of the analysis, the mean score of exercise dependency of male students was found as 54.25 and the mean score of female students was found as 52.72. Although $\bar{x}=54.25>\bar{x}=52.72$, no statistical significance was found between them in terms of score averages ( $p$ $<0.05)$.

\begin{tabular}{c|c|c} 
Table-4. Pearson moment correlation test for exercise addiction according to gender and academic success. \\
\hline Variable & $\begin{array}{c}\text { Relationship/ } \\
\text { significance }\end{array}$ & Exercise Addiction Level \\
\hline \multirow{2}{*}{ Gender } & $\mathrm{r}$ & $-0,079$ \\
\cline { 2 - 3 } & $\mathrm{P}$ & 0,585 \\
\hline \multirow{2}{*}{ Academic Success } & $\mathrm{r}$ & 0,093 \\
\cline { 2 - 3 } & $\mathrm{P}$ & 0,520 \\
\cline { 2 - 3 } & $\mathrm{N}$ & 50 \\
\hline
\end{tabular}

In Table 4, there is a Pearson Moment Correlation test performed to determine the relationship between the participants' gender and academic success and exercise addiction total score. As a result of the analysis, it was determined that there is a low negative relationship between the gender variable $(r=-, 079 ; \mathrm{p}>0.05)$ and the level of exercise addiction, but this relationship is not statistically significant. It was found that there was a low level of positive correlation between academic success variable $(r=, 093 ; \mathrm{p}>0.05)$ and exercise addiction level, but this relationship was not statistically significant $(\mathrm{p}<0.05)$.

\section{Discussion}

Students studying in the schools and faculties providing education in the field of sports are composed of individuals with a certain sports culture and exercise habits. Most of these students appear as people who are actively involved in sports, competing in any sports leagues and grown with sports. Exercise habits of individuals who will be physical education and sports teachers in the future is a subject that should be examined completely in every sense.

In the light of the findings obtained in this study conducted with 50 students studying in Mardin Artuklu University School of Physical Education and Sports, Physical Education and Sports Teaching Program.

It was observed that $\% 52$ of the participants, that is more than half, were addicted to exercise. This is a very high rate. On the other hand, \%38 of the participants are in the risk group. In a study, it was found that individuals who regularly exercise and sports activities have an exercise addiction level of \%56.1 (Costa, Cuzzocrea, Hausenblas, Larcan, \& Oliva, 2012). The result which is obtained by Costa et al. (2012) supports this study. In another study, 305 students studying at the school of physical education and sports were researched, some of them were found to have exercise addiction, and the physical activity levels of this group were high (Gün, 2018).

In the study, it was found that exercise addiction scores of male students were higher than female students, but this difference was not significant. In a study by Hamer and Karageorghis (2007) the same findings were reached and it was found that men score more than women (Hamer \& Karageorghis, 2007). In this study, the researchers obtained a statistically significant difference between the scores of male students and female students. In this aspect, it partially supports this study.

When exercise addiction scores are evaluated according to academic success and gender; As a result of the correlation analysis, a low level of negative correlation was found between the gender variable and exercise addiction. A low level of positive correlation was found between academic success and exercise addiction scores. Although the result does not make a statistical meaning, there is a positive correlation between academic success and exercise addiction. It is thought that more significant differences can be obtained in a study with more participants.

\section{References}

Adams, J., \& Kirkby, R. (2002). Excessive exercise as an addiction: A review Addiction Research and Theory, 10(5), 415-437.

Altun, M. (2019). Examination of general self-efficacy of sudents studying in physical education and sports college and students studying in other faculties. Social Sciences Institute, Department of Physical Education and Sports, Master's Thesis, 34, Bartin, Turkiye. 
Bavlı, O., Kozanoğlu, M., \& Doğanay, A. (2011). The effect of regular exercise participation on exercise addiction $\ulcorner$ Investigation the effects of participation regular exercise on exercise dependence. Selcuk University Journal of Physical Education and Sports Sciences 13, $150-153$.

Berczik, K., Szabó, A., Griffiths, M., Kurimay, T., Kun, B., Urbán, R., \& Demetrovics, Z. (2012). Exercise addiction: Symptoms, diagnosis, epidemiology, and etiology. Substance Use $\S^{2}$ Misuse, 47, 403-417.Available at: 10.3109/10826084.2011.639120.

Chapman, C., \& De Castro, J. (1990). Running addiction: Measurement. Journal Sports Medicine and Physical Fitness, 30, $283-290$.

Costa, S., Cuzzocrea, F., Hausenblas, H., Larcan, R., \& Oliva, P. (2012). Psychometric examination and factorial validity of the exercise dependence scale-revised in Italian exercisers. Journal Behav Addict, 1(4), 186-190.

De Coverley, V. D. (1987). Exercise dependence. British Journal of Addiction, 82(7), 735-740.

Fox, K., \& Boutcher, S. (2004). Physical activity and psychological well-being (pp. 130-153). London: Routledge.

Freimuth, M., Moniz, S., \& Kim, S. (2011). Clarifying exercise addiction: Differential diagnosis, co- occurring disorders, and phases of addiction. International Journal Environ Reserch Public Health, 21(8), 4069-4081.Available at: https://doi.org/10.3390/ijerph8104069.

Gün, A. (2018). Comparison of physical activity and body mass indexes of physical education and sports school students according to exercise addiction status. Erzincan Binali Yıldırım University Health Sciences Institute, Department of Physical Education and Sports, M.Sc. Thesis. Erzincan.

Hamer, M., \& Karageorghis, C. (2007). Psychobiological mechanisms of exercise dependence. Sports Medicine, 37(6), 477-484.Available at: https://doi.org/10.2165/00007256-200737060-00002.

Hausenblas, H. A., \& Symons, D. D. (2002a). Exercise dependence: A systematic review. Psychology of Sport and Exercise, 3(2), 89123.Available at: 10.1016/S1469-0292(00)00015-7.

Landolfi, E. (2013). Exercise addiction. Sports Medicine, 43(2), 111-119.Available at: 10.1007/s40279-012-0013-x.

Ozgül, F., Kangalgil, M., \& Yıldız, R. (2019). Comparison of the academic support perceptions of the physical education and sport teacher candidates with other teacher candidates. Turkish Studies, 14(3), 1649- 1659.Available at: 10.29228/TurkishStudies.22557.

Sussman, S., Arpawong, T., Sun, P., Tsai, J., \& Rohrbach, L. (2011). Prevalence and co-occurrence of addictive behaviors among former alternative high school youth. Behaviour Addictive, 3(1), 33-40.Available at: https://doi.org/10.1556/jba.3.2014.005.

Tekkurşun, G., Hazar, Z., \& Cicioğlu, H. (2018). Exercise addiction scale (EAS): A study of validity and reliability. Kastamonu Education Journal, 26(3), 865- 874.Available at: 10.24106/kefdergi.413383.

$\mathrm{Uz}$, I. (2015). Investigation of exercise addiction in individuals attending fitness centers regularly. Canakkale Onsekiz Mart University Institute of Health Sciences, Master Thesis.

Vardar, E., Vardar, S., \& Toksöz, I. (2012). Exercise dependence and evaluations of psychopathological features. Düsünen Adam The Journal of Psychiatry and Neurological Sciences, 25(1), 51-57.Available at: 10.5350/DAJPN2012250106.

Yıldırım, Y., \& Yıldırım, I. (2016). Egzersiz bağ̌mlılı̨̆̆ depresyon ilişkisi [Relationship between exercise addiction and depression]. In: Zenginbaş, M. Paper presented at the Proceedings Book of the 2nd International Conference on the Changing World and Social Research (ICWSR'2016). October 14-16, Barcelona, Spain. 